\title{
Desarrollo económico y estabilidad democrática: un problema fundamental para la politica comparada latinoamericana
}

\author{
Economic development and democratic stability: a critical issue for \\ Latin American Comparative Politics
}

\section{Federico Traversa}

\section{Resumen}

América Latina experimentó más quiebres de la democracia durante el siglo XX que ninguna otra región. Con frecuencia los latinoamericanos interpretamos estas vicisitudes de nuestras democracias cómo consecuencia de la conflictividad social de nuestra región, que ha sido también la más desigual del planeta. Sin embargo en los últimos ańos cobró fuerza otra teoría: más que de la desigualdad, los quiebres de la democracia habrían sido consecuencia de los bajos niveles de consumo. Esta teoría se deriva de la fuerte asociación estadística entre el PBI y la estabilidad democrática. Este artículo analiza la dimensión teórica del problema, repasando algunos trabajos que sostienen que el incremento en los niveles de consumo promedio favorecería la estabilidad. Se concluye que estos trabajos son a veces inconsistentes y otras veces presentan modelos extremadamente tautológicos, que incluyen supuestos que implican en sí mismos la conclusión esperada. Además se demuestra aquí la consistencia y vigencia de las teorías latinoamericanas que asociaron la inestabilidad democrática a una desigual estratificación social.

\section{Palabras clave}

Teoría de la Modernización Exógena; Mecanismo; Elección Racional; Democracia; Desarrollo Económico.

\begin{abstract}
Latin America experienced more breakdowns of democracy in 20th century than any other region. Latin Americans have related the vicissitudes of their democratic history as a result of the high social conflict associated with unequal peripheral capitalism. However, in recent years, an alternative interpretation emerged: the breakdowns of democracy would have been a consequence of low average levels of consumption. This interpretation is derived from the statistical association between GDP and democratic stability. This article focuses on the theoretical dimension of the problem by analyzing some works which argue that the increase in average consumption favor democratic stability. It is concluded that in some cases the argument is inconsistent, and in others the model proposed includes an initial assumption that implies by itself the final conclusion of the analysis. To demonstrate this point, an analytical model was developed here. Its model also shows that Latin American theories which associated democratic instability with unequal social stratification are absolutely consistent and valid.
\end{abstract}

\section{Keywords}

Exogenous Modernization Theory; Mechanisms; Rational Choice; Democracy; Economic Development. 


\section{Introducción ${ }^{1}$}

Una de las regularidades empíricas más fuertes de la Ciencia Política, es la relación existente entre el desarrollo económico de un país y la presencia de instituciones democráticas estables (ACEMOGLU et al., 2009). En las últimas décadas, un profundo interés ha despertado por los mecanismos teóricos que podrían explicar esta relación empírica (WUCHERPFENNIG y DEUTSCH, 2009). Algunos autores han sugerido que la relación entre desarrollo económico y estabilidad democrática estaría mediada por factores de tipo distributivo (BOIX, 2003; ACEMOGLU y ROBINSON, 2005) o culturales (INGLEHART y WELZEL, 2005). Por otro lado, Przeworski (2005) ha sido el primero en señalar que la relación no tiene porqué explicarse por factores intervinientes, en tanto el desarrollo económico incidiría directamente en una mayor duración de la democracia una vez que esta fuera establecida en un país - hipótesis que el autor ha denominado 'teoría exógena de la modernización'.

De existir una conexión causal directa entre el desarrollo económico y la estabilidad de la democracia, ésta tendría particular interés para América Latina por cuatro importantes razones. En primer lugar, porque América Latina y el Caribe fue la región del mundo donde la democracia tuvo un comportamiento más inestable durante el siglo $\mathrm{XX}^{2}$. En segundo lugar porque, a pesar de este magro desempeño en materia de estabilidad democrática, América Latina ha sido generalmente considerada una región de desarrollo económico intermedio. En tercer lugar - y ligado a lo anterior - porque uno de los principales aportes de la Ciencia Política latinoamericana ha sido la crítica a la Teoría de la Modernización, señalando que América Latina escaparía a la relación general estipulada entre desarrollo y democracia (O'DONNELL, 1973). Finalmente, porque la pretendida relación causal directa entre desarrollo y democracia viene a opacar el rol de la desigualdad y la conflictividad distributiva como factor interviniente, y es justamente la desigualdad la principal característica distintiva de nuestra región, señalada además por nuestros académicos como el principal factor de inestabilidad

\footnotetext{
1 Agradezco la muy valiosa ayuda de Álvaro Forteza (UdelaR) y los comentarios de dos revisores anónimos. Todos los errores y omisiones son única responsabilidad del autor.

${ }^{2}$ Según la clasificación de Boix, Miller y Rosato (2012) en cien años (1901-2000) la región experimentó 28 quiebres de la democracia y prácticamente todos los países de la región vivieron alguna vez un episodio democrático que resultó fallido debido a un golpe de Estado.
} 
democrática en el capitalismo periférico (CARDOSO y FALETTO, 1969; PREBISCH, 1981) $)^{3}$.

Por otra parte, la existencia de una relación directa entre el desarrollo económico y la estabilidad democrática tendría un enorme valor práctico en relación a las estrategias para la promoción de la democracia. Los ciudadanos y políticos de países muy pobres y desiguales podrían hallarse en medio de un gran dilema, dadas las reconocidas tensiones existentes entre los objetivos redistributivos y la eficiencia económica en economías capitalistas (OKUN, 1972). Una disyuntiva trascendente surge entonces: ¡es imprescindible mejorar la distribución del ingreso para asegurar la estabilidad democrática (ACEMOGLU y ROBINSON, 2005; BOIX, 2003)? ¿O bastaría focalizarse en el desarrollo económico confiando en que este será capaz de asegurar la duración de la democracia (TAYDAS y PEKSEN, 2012; MCBRIDE, MILANTE y SKAPERDAS, 2011)?

Como se señaló anteriormente, Przeworski ha argumentado que el desarrollo económico tiene una relación directa con la estabilidad democrática. El autor ha expuesto su argumento en distintas publicaciones y de distinta forma. La explicación más influyente se desarrolla a partir de un modelo teórico que supone un extenso análisis algebraico. Sin embargo, como se analiza aquí, este modelo de Przeworski (2005) incluye un supuesto sobre la utilidad del consumo, que implica en sí mismo la conclusión final que se quiere demostrar ${ }^{4}$. Esto transforma su esfuerzo teórico en una tautología. Además, si se altera levemente éste supuesto sobre la utilidad del consumo, la conclusión fundamental del modelo se desmorona, y ya no es posible concluir que un incremento en el nivel de renta per cápita favorece la estabilidad de la democracia ${ }^{5}$.

\footnotetext{
${ }^{3}$ Desde un punto de vista empírico, América Latina ha sido "la piedra en el zapato" para la relación entre desarrollo económico y estabilidad democrática, ya que muchos de los quiebres de la democracia que se produjeron en países que contaban con un nivel alto de PBI per capita se registraron en ésta región.

${ }^{4}$ El supuesto fundamental al que nos referimos tiene que ver con el modo en que los ingresos se transforman en utilidad para los ciudadanos. Przeworski propone una función de utilidad en la que: a) la utilidad que reporta el consumo para los ciudadanos siempre es menor en una dictadura que en una democracia, y b) la fracción en que se reduce la utilidad del consumo al vivir en dictadura es una proporción del total consumido. En tal sentido, y gracias al segundo supuesto (b), si el total consumido aumenta con el ingreso per cápita de un país entonces también aumentan las pérdidas de utilidad que implicaría vivir en dictadura a medida que un país se vuelve más rico.

${ }^{5}$ Es necesario aclarar que estos problemas no invalidan la originalidad de la idea de Przeworski. Aunque el modelo no agrega nada al argumento, la democracia pudo estabilizarse directamente como consecuencia de los niveles de consumo según el mecanismo propuesto el autor y este es un mérito
} 
En otras ocasiones, Przeworski (2006 y 2008) ha afirmado que la relación causal entre la estabilidad democrática y los niveles de renta per cápita puede demostrarse mediante un argumento alternativo, que únicamente requeriría aceptar el supuesto de la utilidad marginal decreciente del consumo. Lamentablemente en estos casos el autor simplemente enuncia la afirmación y expone su aparente validez de un modo gráfico, sin desarrollar paso a paso los fundamentos últimos que sustentarían la explicación. Este segundo argumento, que sólo requeriría aceptar la utilidad marginal decreciente del consumo, también ha resultado de gran influencia, y su validez podría despejar muchas dudas sobre los mecanismos que ligan al desarrollo económico con la estabilidad democrática. Sin embargo aquí, mediante el desarrollo de un modelo alternativo, se demuestra que la utilidad marginal decreciente del consumo no alcanza en modo alguno para suponer que la democracia se estabiliza como consecuencia de un incremento de los niveles de renta per cápita.

El artículo se organiza en tres partes. En la primera de ellas, se analiza el modelo original propuesto por Przeworski (2005) y se demuestra que una de sus premisas implica en sí misma la conclusión del análisis, transformando la propuesta en una tautología.

En la segunda parte, se desarrolla un modelo teórico que sustituye la función de utilidad del consumo propuesta por Przeworski (2005) con una función de utilidad muy similar, que respeta el supuesto de utilidad marginal decreciente del consumo. Como resultado de este modelo analítico puede demostrarse: a) que contrariamente a lo afirmado por Przeworski (2006 y 2008) la utilidad marginal decreciente del consumo no es condición suficiente para suponer que la democracia se estabiliza por el mero incremento de la renta media, b) que un sólo cambio en la función original de consumo propuesta por Przeworski (2005) desmorona las conclusiones a las que había arribado en este modelo y c) que en la lógica de este modelo, las comparaciones interpersonales de ingreso unidas a una desigual distribución sí vuelven más inestables a la democracia (cómo se interpretó en general por parte de los teóricos latinoamericanos: Prebisch (1981) y O'Donnell (1973)).

indudable. Sin embargo la popularidad del argumento - a pesar de la futilidad del modelo dada su tautología - sumado a las inconsistencias de los otros dos trabajos, indican que muchos politólogos que popularizan la explicación tal vez no la comprenden a cabalidad. Por eso aquí se quiere remarcar que otras explicaciones de la estabilización (en especial las relacionadas con los conflictos distributivos) siguen tan vigentes como antes y no son invalidadas por el modelo de Przeworski. En puridad aún no sabemos exactamente que produjo la estabilización y las viejas teorías del conflicto siguen siendo una explicación tan plausible como antes. 
La tercera parte del artículo se dedica a discutir la plausiblidad empírica y teórica de la función original sobre la utilidad del consumo propuesta por Przeworski (2005), en el entendido de que la validez de los supuestos es un punto importante para todo modelo teórico y muy especialmente en este caso, en tanto sus conclusiones dependen enteramente de una sola de sus premisas (MORTON, 1999; CLARKE y PRIMO, 2007). Se espera que el artículo aporte nuevos insumos al debate en torno a los mecanismos que explican la creciente estabilización de las democracias contemporáneas, revigorizando el estudio de un problema que ha sido central para la Ciencia Política, particularmente en América Latina.

\section{'Mecánica Popular' para una vieja correlación}

Desde hace varios años, Przeworski ha señalado que no existen dudas respecto a que la probabilidad de que una democracia sobreviva se incrementa con el ingreso per capita: "puede controlarse por cualquier cosa, desde la pileta de la cocina hasta el altillo de tu abuela. Esta relación sobrevivirá cualquier cosa. Es monotónica y fuerte, increíblemente fuerte. No tengo un trazo de dudas respecto a eso" (MUNCK y SNYDER, 2007, p. 470) ${ }^{6}$. Esta relación ha merecido diversos cuestionamientos empíricos, además de que es necesario comprender la explicación teórica subyacente a asociación estadística entre el desarrollo económico y la duración de la democracia (PRZEWROSKI et al., 2000).

Ha sido el propio Przeworski (2005) quien ha desarrollado un modelo teórico que propone una relación directa entre el desarrollo y la duración de la democracia. Este modelo se ha vuelto muy popular - es ampliamente citado en la literatura especializada $-\mathrm{y}$ aporta la mecánica o microfundamentos que sustentarían una relación directa entre aumento del producto y estabilidad democrática. A pesar del alto impacto que ha tenido el citado modelo, es razonable dudar que todos quienes lo conocen y lo citan realmente lo entiendan. Cómo se demostrará ahora, toda la elegante álgebra del modelo podría haberse ahorrado, pues su conclusión ya está implícita en uno de sus supuestos.

Según el modelo de Przeworski (2005) en cada elección se enfrentan dos partidos, uno que representa a los pobres y otro a los ricos, cada uno proponiendo una tasa de redistribución del ingreso. El resultado de la elección es una instrucción para los partidos respecto a lo que deberían hacer: el ganador podrá ocupar el gobierno y el

\footnotetext{
${ }^{6}$ Entrevista personal de los autores a Adam Przeworski, la traducción de éste y los siguientes fragmentos es propia.
} 
perdedor debería aceptar el resultado, esperando triunfar en la próxima elección. Sin embargo, el partido perdedor también podría tomar otro curso de acción, y rebelarse frente al resultado. Si lo hace, sabe que el ganador intentará castigar su acción, y que a ambos les espera un enfrentamiento violento.

En este enfrentamiento violento, cada uno de los contendientes tiene algunas probabilidades de vencer, y para quien consiga triunfar por la fuerza le será más conveniente imponer su propia dictadura que respetar la democracia. Por lo tanto, si el partido perdedor de la elección decide levantarse en contra de la democracia, el resultado final será irremediablemente una dictadura. Quien consiga transformarse en dictador podrá imponer sus pretensiones distributivas, pero al mismo tiempo generará entre los derrotados una sensación de inseguridad que afectará la utilidad de todo lo que consuman.

El autor propone entonces la función de utilidad del consumo (1), donde la utilidad que se extrae de lo consumido por parte de cada individuo depende del régimen de gobierno, y de su apoyo o no al gobierno en el caso existir dictadura. En esta función $c$ significa consumo, mientras que $\mu$ es un parámetro que afecta la utilidad del consumo y depende del régimen de gobierno y de quien gobierna. Este parámetro vale uno $(\mu=1)$ para toda la población si existe una democracia, y también para aquella parte de la población que respalda al gobierno en el caso de existir una dictadura. Pero este parámetro será menor a uno para la población que vive en una dictadura y no respalda al gobierno $(0<\mu<1)$.

$$
U(c)=\mu \log c
$$

La probabilidad de que se produzca el enfrentamiento violento que quiebre la democracia depende entonces de una serie de variables: de la tasa de imposición que estaría dispuesto a imponer el gobierno elegido democráticamente (que motiva el descontento en el partido perdedor), de la fuerza relativa de cada uno de los partidos contendientes si se produjera un enfrentamiento violento, y sobre todo del valor que reporta vivir en una democracia o en una dictadura. Los partidos evalúan todas estas variables y deciden finalmente que curso de acción tomar.

En apariencia se trataría de un modelo sobre los conflictos distributivos, en tanto el motivo último del enfrentamiento entre ricos y pobres, parece descansar en las preferencias impositivas de cada grupo. Luego de algunas páginas de cálculos precisos y elegantes, es posible para Przeworski demostrar que las probabilidades de rebelión frente a los resultados democráticos disminuirán consistentemente con el incremento 
del producto per capita de una sociedad. Sin embargo, este resultado no es nada sorprendente, la función (1) es tan influyente, que si se la observa con atención, podríamos incluso ahorrarnos el análisis algebraico.

De esta sencilla función (1) en realidad se desprende todo lo que vendrá después. En efecto, a partir de este supuesto tenemos un acercamiento interesante respecto a la utilidad que representa la democracia. Como se ha dicho la utilidad del consumo bajo una democracia es igual a (1.1) para toda la población. Es obvio entonces, en la medida que $\mu=1$ para toda la población si hay democracia, que la democracia siempre asegura a toda la población la máxima utilidad posible de todo lo que se consume:

$$
\text { (1.1) } \quad U(c)=\log c
$$

Mientras tanto, si se produce un enfrentamiento violento entre los partidos, cualquiera de los dos cuenta con posibilidades de imponerse al otro. El partido triunfador por la violencia conseguirá transformarse en dictador, y la utilidad de su consumo sigue dependiendo de la misma función de utilidad (1.1). Pero los seguidores del partido perdedor sufrirán pérdidas de utilidad en todo lo que consuman, estas pérdidas se miden por el parámetro de la función (1). Embarcarse en un conflicto violento, implica entonces el riesgo de sufrir estas pérdidas. 
Figura 1 - Utilidad del consumo para los opositores según tipo de régimen e ingreso per capita (a)

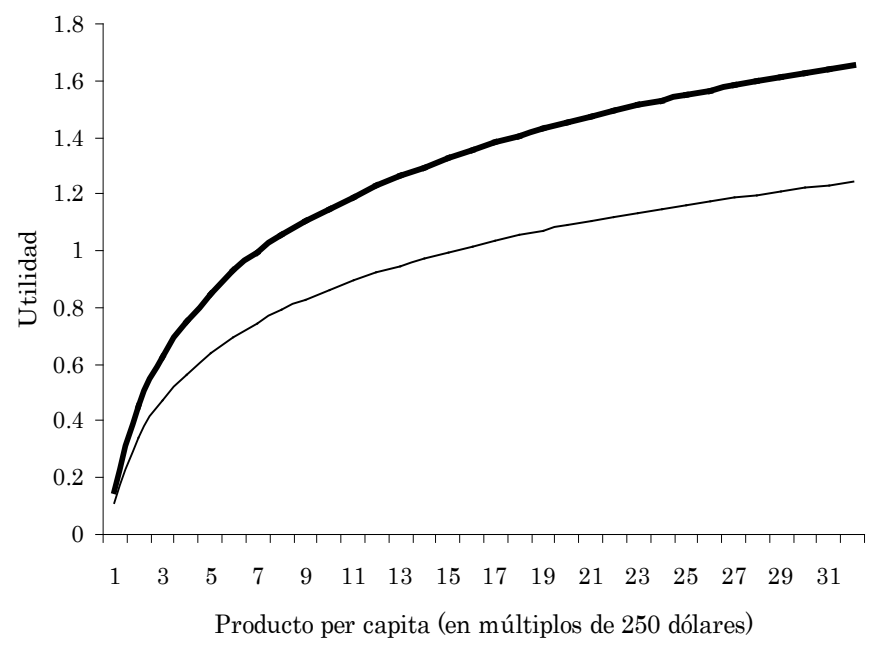

(a) Democracia (línea continua trazo grueso) y dictadura (línea continua trazo fino).

Fuente: Elaboración propia.

Lo que puede pasar desapercibido en este planteo, es que las pérdidas asociadas con estos riesgos, son por definición cada vez más grandes conforme que aumenta el producto y el consumo. Incluso tienden a infinito cuando el producto tiende a infinito. Con un supuesto como éste, no es de extrañar el resultado final del modelo. En el Gráfico 1 se ilustra la utilidad del consumo para los ciudadanos opositores, según vivan en una democracia (línea de trazo grueso) o en una dictadura (línea de trazo fino) y conforme que aumenta el producto per capita de la sociedad. El producto está expresado en múltiplos de 250 dólares, y hemos supuesto que $\mu=0.7$. Como puede apreciarse, a bajos niveles de producto las diferencias de utilidad potencial entre una democracia y una dictadura son pequeñas, pero estas diferencias se incrementan con el aumento del producto.

Por definición, atentar contra la democracia supone ingresar en una confrontación violenta, donde se arriesga más utilidad, cuanto más rica sea una sociedad. Es obvio entonces que dado este supuesto y a todo lo demás constante, existirá cierto nivel del producto en el cuál a ningún grupo ya le resulte razonable desobedecer a la democracia. El álgebra posterior, aunque impecable, es redundante e innecesaria para llegar a esa conclusión ineluctable y prefigurada desde el inicio. La situación tal vez sea ilustrativa de lo que sucede con algunos complejos modelos que tal vez por propia sofisticación - gozan de un importante prestigio entre una audiencia 
que puede incluso no comprenderlos del todo, pero igualmente los cita y contribuye a multiplicar su legitimidad e impacto.

\title{
¿Traspasando la frontera de la tautologia?
}

Przeworski (2005) ha presentado su modelo como un intento de encontrar un argumento deductivo que explique sus hallazgos empíricos previos (PRZEWORSKI y LIMONGI, 1997; PRZEWORSKI et al., 2000). El problema es que la función (1) vuelve al modelo particularmente recursivo, transformándolo en una tautología, tanto en términos lógicos como retóricos. En realidad, desde un punto de vista estrictamente lógico todo modelo deductivo válido resulta en una tautología y esto no representa un problema en sí mismo (WITTGENSTEIN, 1999) ${ }^{7}$. Sin embargo el modelo de Przeworski también constituye una tautología de acuerdo con la acepción corriente del término, esto es, una construcción retórica de un argumento circular. Aristóteles fue el primero en analizar y considerar este tipo de problemas en la argumentación:

\begin{abstract}
Siempre que un hombre intenta probar lo que no es evidente por sí mismo a través de sí mismo, entonces vuelve a lo del principio (petittio principii) postula aquello que es preciso demostrar. Esto puede hacerse asumiendo de una vez cómo válido aquello que está en discusión, (pero) también es posible hacer una transición a través de otras cosas que naturalmente pueden ser fácilmente probadas si se acepta la tesis inicial, y demostrar luego a través de ellas (ARISTÓTELES, 2012).
\end{abstract}

Este tipo de tautologías resultan de "asumir lo que se debe probar" (ROBINSON, 1971, p. 113) o "basar una conclusion en un supuesto que necesita tanta prueba que demuestre su validez como la conclusión en sí misma" (GARNER, 2001, p. 101). Más aún, "la transición a través de otras cosas que naturalmente pueden ser probadas si se acepta la tesis inicial, y demostrar luego a través de ellas" que menciona Aristóteles (2012, p. 216), inevitablemente recuerda a la complejidad algebraica del modelo de Przeworski. Esta complejidad ayuda a oscurecer el hecho de que las conclusiones ya están implícitas en una de las premisas respecto a la utilidad del consumo ${ }^{8}$.

\footnotetext{
${ }^{7}$ Cómo señala Bertrand Russell (2009, p. 76) "todo lo que es una proposición lógica debe ser en algún sentido u otro una suerte de tautología"

${ }^{8}$ Hurley (2008) indica que un modo de falacia es dejar fuera de la argumentación a una premisa clave y discutible, mientras se genera la ilusión de que nada más se necesita para alcanzar a establecer la conclusión final. El modelo de Przeworski enumera claramente las premisas del modelo, pero su premisa
} 
Estas críticas se relacionan con el estilo usado por Przeworski, y en términos estrictos no cuestionan la validez interna de su modelo. Como explica Perelman (1979):

[...] el orador que construye su discurso sobre premisas no aceptadas por la audiencia comete una falacia clásica de la argumentación - a petitio principii. No se trata de un error en la lógica desde un punto de vista formal, pero si de una falencia en la argumentación, en tanto el orador elude la cuestión central, presuponiendo la existencia de una conformidad que no existe, y a la que debería en realidad dirigir sus esfuerzos (PERELMAN, 1979, p. 14-15).

Un modelo que postule una incidencia directa del desarrollo económico sobre la estabilidad democrática se vuelve trivial, si ésta conclusión se deriva directamente de uno solo de sus supuestos. Tal vez por ello, el autor ha afirmado en varias ocasiones que las mismas conclusiones podrían obtenerse con otra función de utilidad del consumo. En tal sentido, Przeworski (2005, 2006 y 2008) ha sostenido que los efectos estabilizadores del producto per cápita sobre la democracia también podrían concluirse si se postula una función de utilidad que únicamente respetase el supuesto de la utilidad marginal decreciente del consumo. Lamentablemente en este caso el autor no desarrolla un modelo teórico que explique cómo sería esto posible 9 .

El punto propuesto y no demostrado por Przeworski, es particularmente interesante, porque el supuesto de utilidad marginal decreciente del consumo resulta sumamente razonable y resultaría notablemente clarificador que de él pudiera derivarse que la democracia se estabiliza con el aumento de la renta per cápita. En la medida que este punto no fue analizado en profundidad hasta ahora, en la próxima sección se estudia la validez de la afirmación de Przeworski a partir de un modelo en el cual los niveles de ingreso absoluto varían, las personas obtienen más utilidad del consumo viviendo en dictadura que en democracia, y el ingreso está sujeto a una utilidad marginal decreciente.

clave sobre la utilidad del consumo aparece mezclada con otros supuestos entretejiendo un modelo innecesariamente complicado. Esta complejidad oscurece el hecho de que las conclusiones dependen enteramente de una sola premisa.

${ }^{9}$ En este caso el autor sólo ha expuesto gráficamente su idea. 


\section{El aumento del PBI per cápita y la utilidad marginal decreciente del consumo no son suficientes para explicar la estabilidad democrática}

En algún sentido, la tautología implícita en la función de utilidad analizada en la sección anterior parece ser reconocida por el autor cuando detalla las conclusiones de su análisis en este fragmento que denominaré (i):

La democracia siempre sobrevive cuando una sociedad está suficientemente desarrollada. La dependencia de los ingresos en esta historia proviene tanto de la aversión a la inseguridad física, a partir de la suposición de que las personas disfrutan menos de cualquier cantidad de consumo cuando se enfrentan a la posibilidad de opresión física, y de la aversión al riesgo (PRZEWORSKI, 2005, p. 265).

Esto resultaría en admitir que la conclusión del modelo depende de uno de sus supuestos, y por lo tanto su capacidad heurística se vería claramente afectada. Tal vez por eso, el pasaje anterior continúa inmediatamente con un nuevo fragmento (ii) que incluye una afirmación extraña y que no fue comprobada en su modelo:

Sin embargo, la dependencia (de la estabilidad democrática) del nivel de
renta per cápita, y el resto de los resultados, también podrían sostenerse si
supusiéramos que la gente tiene una preferencia por la democracia,
independientemente del nivel de ingreso. La interpretación de los
resultados sería que a medida que la utilidad marginal del consumo
disminuye, la preferencia por la democracia (o en contra de la dictadura)
supera la eventual ganancia en consumo que tendría quien se convirtiera
en un dictador. No puedo distinguir estas dos interpretaciones
(PRZEWORSKI, 2005, p. 265).

Este pasaje (ii) es particularmente curioso. Luego de interpretar los resultados del modelo teórico, aquí el autor introduce otra explicación que no fue comprobada, afirmando que es válida. Más aún, señala que no es capaz de distinguir entre la interpretación que expone en el pasaje (i) y la que propone en (ii). Este asunto que el autor no llega a explicar no es algo secundario, sino que es lo fundamental. Los modelos sustentados en la lógica de la acción racional intentan dejar al descubierto los mecanismos que explican las relaciones entre fenómenos o variables (MORTON, 1999). ¿Cómo aceptar entonces una explicación de la relación entre la democracia y el desarrollo económico, si finalmente su autor concluye que no puede distinguir cuál es mecanismo preciso que explica la mayor duración de la democracia en su modelo? 
Por otra parte, ambas explicaciones son muy diferentes. La primera (i) es la que se analizó en la sección anterior, se trata de un postulado interesante, aunque su mera aceptación vuelve innecesario y tautológico a todo el modelo analítico desarrollado. La segunda explicación (ii) involucra únicamente al supuesto de utilidad marginal decreciente del ingreso. Esta afirmación no fue probada en el modelo. Y habríamos avanzado notablemente si pudiera comprobarse que la mera aceptación del supuesto de la utilidad marginal decreciente del ingreso permite entender la relación entre estabilidad democrática y desarrollo económico.

Tal vez por ello en dos trabajos subsiguientes Przeworski (2006 y 2008) afirma que bastaría el supuesto de utilidad marginal decreciente del ingreso para explicar porqué el desarrollo económico favorece la estabilidad democrática. Según el autor, si el ingreso (o consumo) tiene una utilidad marginal decreciente, en las sociedades más ricas la democracia podría sostenerse puesto que los conflictos distributivos serían menos acuciantes. Conforme lo que se pierde en un conflicto es menos valioso producto de la utilidad marginal decreciente del dinero, la población estaría dispuesta a sacrificar estas pérdidas con tal de sostener la democracia.

Sin embargo en ninguno de estos trabajos el autor ha ofrecido los fundamentos precisos de esta sugestiva conjetura. Y aunque el razonamiento sea persuasivo y luzca sólido, no es en realidad consistente. En primer lugar vale la pena analizarlo de modo gráfico tal como lo hace el propio autor ${ }^{10}$, para explicar donde radica el problema en la intuición propuesta por Przeworski. Supongamos entonces siguiendo al autor, que tenemos dos países $A$ y $B$, con la misma distribución del ingreso, la misma valoración de la democracia, y las mismas capacidades de ricos y pobres para luchar por imponer una dictadura. Supongamos por último que la única diferencia entre ambos países es el ingreso per cápita, que en el país $A$ es cuatro veces mayor que el del país $B$. Siguiendo al autor, en $A$ deberían existir mejores probabilidades de sostener la democracia, ¿pero esto es así?

En primer lugar es necesario definir qué tasa de imposición se elegirá en cada país. Supongamos, como es habitual, que en ambos países se impondrá la tasa preferida por el votante mediano. Si la distribución del ingreso es la misma en $A$ y en $B$ (al igual que todas las demás variables económicas salvo el PBI per cápita) entonces deberá aplicarse la misma tasa impositiva en ambos países. Esta conclusión es compartida por todos los modelos redistributivos sustentados en el Teorema del Votante Mediano, en

\footnotetext{
${ }^{10}$ Véase Przeworski (2006).
} 
tanto el votante mediano elige su tasa óptima en función de dos variables, la distribución del ingreso antes de impuestos y los costos asociados a la redistribución ${ }^{11}$.

Como en $A$ y en $B$ la distribución del ingreso es idéntica, es claro que tanto el ingreso del votante mediano como el ingreso promedio de la economía son el cuádruple en $A$ que en $B$, por lo tanto la relación entre ambas variables es idéntica en ambos países, y la tasa de impuestos óptima para el votante mediano también. En tanto la tasa de impuestos ganadora en democracia es la misma, hemos de suponer entonces que lo único que diferirá en ambos países es el monto total de lo recaudado en términos absolutos, que será el cuádruple en $A$ que en $B$, dado que el producto total también es el cuádruple.

Ahora bien, aquí ingresa por fin el problema de la utilidad marginal decreciente del ingreso. ¿ ¿Hay más tolerancia a la redistribución en $A$ que en $B$ y esto significará un mayor respeto a las decisiones democráticas? ¿Si la democracia tiene la misma utilidad en ambos países, se sostendrá la democracia en $A$ producto de la utilidad marginal decreciente del ingreso que le resta relevancia a los conflictos distributivos? Para responder estas preguntas es necesario calcular la pérdida de utilidad que provoca la redistribución en cada país. Como ya se ha dicho, sabemos que el monto redistribuido será cuatro veces más grande en $A$ que en $B$. Pero en cambio sabemos que la utilidad marginal decreciente del ingreso hace que este monto redistribuido represente también menos utilidad en A que en $B$.

La Figura 2 ilustra el problema ${ }^{12}$. Supongamos que en la sociedad $A$ el producto total es igual a $\$ 8000$ (punto 32 del gráfico) y que en la sociedad $B$ el ingreso total es igual a $\$ 2000$ (punto 8 del gráfico). Supongamos que el monto total redistribuido equivale a una cuarta parte del ingreso total, es decir $\$ 2000$ en $A$, y $\$ 500$ en $B$, ¿en que país representa este monto una mayor utilidad, pudiendo entonces agudizar las tensiones redistributivas? La respuesta es clara, en ambos países la utilidad es la misma.

\footnotetext{
${ }^{11}$ El PBI per cápita no pesa por sí sólo en la elección del votante mediano, lo que él evalúa es la relación de su ingreso con respecto al PBI per cápita (en otras palabras su posición relativa en la distribución del ingreso).

${ }^{12}$ Este gráfico reproduce exactamente la lógica del gráfico de Przeworski (2006) salvo que se proyectan aquí las áreas grises que representan la utilidad total asociada al monto redistribuido.
} 
Figura 2 - Utilidad marginal decreciente del ingreso y redistribución

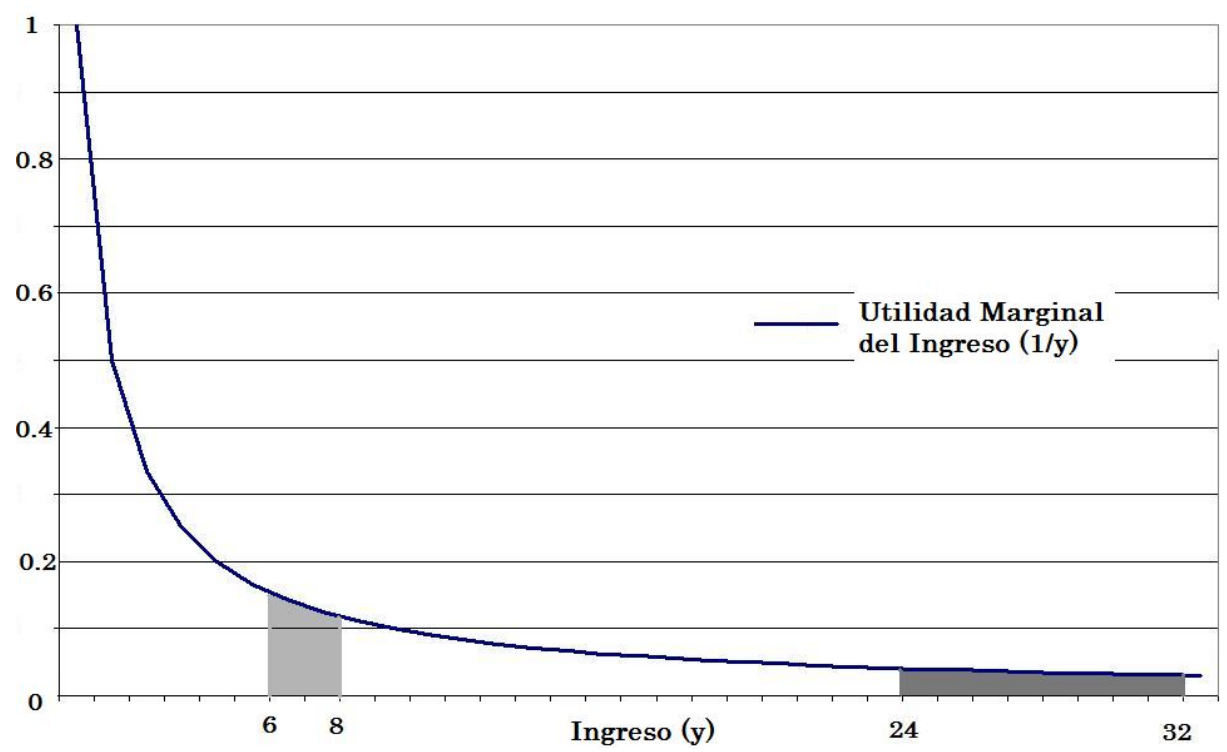

Fuente: Elaboración propia.

Como se aprecia, el área achatada en gris oscuro correspondiente a la utilidad en el país $A$, tiene la misma superficie total que el área más alta correspondiente al país $B$. En $A$ se reparte más ingreso, pero como este país es más rico, producto de la utilidad marginal decreciente del dinero la utilidad que representa el monto a redistribuir es idéntica en ambos países. Este resultado no es casual, sino generalizable a todas las situaciones. En realidad la utilidad marginal decreciente del ingreso no representa ningún efecto sobre la estabilidad democrática de dos países con distinto producto per capita si suponemos que el valor de la democracia es constante, y que todas las demás variables son idénticas. Para alcanzar un resultado distinto es necesario establecer un supuesto ex ante que por definición determine que la democracia valga cada vez más en países más ricos, como hace Przeworski (2005).

\section{Desarrollo analitico del problema}

El problema que recién se ilustró de forma intuitiva, puede desarrollarse en detalle de modo algebraico para despejar dudas. Esto es lo que se hace a continuación, mediante un modelo que además repite al detalle el modelo original propuesto por Przeworski, cambiando únicamente la función de utilidad del consumo. De tal modo 
el desarrollo que sigue permite demostrar que la utilidad marginal decreciente del consumo no es condición suficiente para una creciente estabilización de la democracia con el aumento de la renta media y, simultáneamente, que el modelo original de Przeworski no soporta una transformación en uno solo de sus supuestos.

Consideremos una sociedad con un ingreso per cápita $(y)$ - medido en múltiplos de $\$ 250$ - y consistente en dos tipos de individuos: una proporción $\pi>0.5$ de los agentes es pobre y la fracción restante $(1-\pi)$ es rica ${ }^{13}$. Los ingresos de los pobres son menores a la media, mientras que los ingresos de los ricos son mayores que la media, tal que $\alpha p<1<\alpha r$ donde $\alpha i$ es un múltiplo del ingreso medio ${ }^{14}$. Dos partidos compiten en elecciones, y el sistema democrático determina una tasa de impuestos no negativa, cuya recaudación es redistribuida mediante un monto fijo e igual para todos los ciudadanos.

Todos los agentes tienen preferencias de un solo pico respecto a la tasa impositiva, y en tanto hay más agentes pobres que ricos, el votante mediano es un ciudadano pobre y la existencia de democracia determina que la tasa de impuestos implementada será aquella preferida por los pobres $\tau p$. Como resultado de la elección los individuos según su grupo original (ricos o pobres) obtendrán un ingreso final luego de la redistribución que es un múltiplo del ingreso promedio, siendo la utilidad de este resultado democrático para un grupo cualquiera $i$ igual a $U(s d i y)$. Dados los resultados de la elección, los ricos deciden su curso de acción $A \in\{$ obedecer, rebelarse $\}$ o $\{O, R\}$.

$\mathrm{Si}$ los ricos obedecen se verifican actividades productivas, los ingresos son redistribuidos de acuerdo a la tasa $\tau p$ y más tarde consumidos, hasta que finalmente luego de un período una nueva elección tiene lugar. Por motivos de simplicidad asumiré que los pobres tienen menos motivos que los ricos para rebelarse en contra de la democracia en primer lugar ${ }^{15}$. Solo si los ricos se rebelan un conflicto tienen lugar, y como resultado de este conflicto violento el grupo que prevalece establece su propia dictadura. Así, para evitar la proliferación de casos asumiremos que si un conflicto tiene lugar entre ricos y pobres el grupo triunfador por la fuerza siempre se transforma en dictador. Este supuesto también es consistente con el análisis de Przeworski (2005)

\footnotetext{
${ }^{13}$ Aunque todos los resultados del modelo pueden mantenerse considerando una sociedad integrada por tres clases de individuos aquí se trabaja con dos clases con la finalidad de simplificar el análisis.

${ }^{14}$ Además existe un ingreso de subsistencia (no de mercado) cuya proporción es $\alpha s<\alpha p$.

15 Este supuesto es bastante plausible dada la evidencia empírica (HOBSBAWM, 1990; HUNTINGTON, 2012), y también resulta razonable en tanto el votante mediano es un ciudadano pobre, y él será quien decida la tasa de impuestos a cobrarse bajo el régimen democrático.
} 
quién concluye que en el caso de producirse un conflicto cada grupo encontrará más conveniente establecer su dictadura que defender la democracia.

La probabilidad de que el grupo pobre se imponga en un conflicto violento es igual a $q(0<q<1)$, mientras que la probabilidad de que el grupo rico salga victorioso es igual a $(1-q)$. Bajo su dictadura el grupo victorioso - cualquiera éste sea redistribuye el ingreso dando a los derrotados un múltiplo $s$ de $y$, y distribuyendo el resto entre sus partidarios. Si el grupo de los ricos (pobres) se transforma en dictador dará entonces un múltiplo $s R(s P)$ a los ricos (pobres) y $s$ a los pobres (ricos). La utilidad de un grupo - rico o pobre - que se transforma en dictador es igual a $U($ Siy $) \equiv U i$ mientras que la utilidad de los derrotados que sufren la dictadura del otro grupo es igual a $U s=U(s y)$, siendo siempre $S i>s$.

Asimismo, y al igual que como sostiene Przeworski, supondremos que las dictaduras no sólo redistribuyen ingreso, sino que usan la fuerza para reprimir a los opositores. Cómo resultado los derrotados en una elección democrática extraen más utilidad del consumo que los que son oprimidos por un régimen dictatorial. Propondré entonces una función de utilidad del consumo consistente con este supuesto (2) que como cómo puede apreciarse es apenas diferente a la original propuesta por Przeworski (1). Esta función (2), al igual que la original, es consistente con dos principios: respeta el principio de utilidad marginal decreciente del consumo y también el supuesto de que para los opositores el consumo representa siempre más utilidad en una democracia que en una dictadura.

$$
U(c)=\log (\mu c)
$$

En esta función $c$ representa el consumo, mientras que el parámetro $\mu=1$ para toda la población bajo una democracia y también para el dictador y su grupo de apoyo (sean ricos o pobres) en una dictadura. Mientras tanto $\mu<1$ para los ciudadanos opositores en una dictadura. Por lo tanto, bajo una democracia el consumo de un individuo $i$ es igual a:

$$
\begin{aligned}
& c i=(1-\tau p) y i+\tau p y(1-\lambda \tau p)=[\alpha i+\tau p(1-\alpha i-\lambda \tau p)] y \\
& \quad \equiv s d i y,
\end{aligned}
$$

Donde $\tau p$ es el la tasa de impuestos preferida por el votante decisivo - cuyo ingreso es menor a la media - mientras que $\lambda$ es el costo de eficiencia asociado con el 
impuesto y $2 \lambda y$ es la pérdida de eficiencia marginal por la redistribución. Por lo tanto el consumo del votante pobre se maximiza cuando

$$
\tau p= \begin{cases}\frac{1-\alpha_{p}}{2 \lambda} & \text { si } \frac{1-\alpha_{p}}{2 \lambda} \leq 1 \\ 1 & \text { si } \frac{1-\alpha_{p}}{2 \lambda}>1\end{cases}
$$

En la medida que en equilibrio ambos partidos convergen a $\tau p-$ no olvidemos que el mediano es pobre - cada grupo obtiene bajo democracia la utilidad instantánea:

$$
\begin{aligned}
U i(\tau p) & \equiv U[c i(\tau p)]=\log s d i(\tau p) y \\
& =\log [\alpha i+\tau p(1-\alpha i-\lambda \tau p)]+\log y
\end{aligned}
$$

que es la misma sin importar que partido gane la elección. En cambio la utilidad de los ricos bajo su propia dictadura es $U r=\log s R y$, y bajo la dictadura de los pobres es igual a $U_{s}=\log s \mu y$. Entonces para los ricos la utilidad esperada de un conflicto del cuál puede sobrevenir una dictadura es:

$$
E U r(R)=(1-q) U r+q U s
$$

La decisión del grupo rico de obedecer o rebelarse a la tasa de impuestos democrática depende de la comparación de las utilidades instantánea $(U i(\tau p)$ y $E U r$ $(R))$ y la estabilidad de la democracia depende por completo de esta decisión

Proposición Los ricos optan por la democracia si $U r(\tau p) \geq E U r(R)^{16}$ :

$$
\begin{aligned}
& \log [\alpha r+\tau p(1-\alpha r-\lambda \tau p)]-(1-q) \log s R-q \log s \\
& \quad \geq q \log \mu
\end{aligned}
$$

Como se aprecia, tanto el término que se encuentra a la derecha como el que está a la izquierda de (2.5) son constantes sin depender del nivel de ingreso per cápita ${ }^{17}$. En consecuencia la estabilidad democrática depende únicamente de algunos parámetros específicos: la distribución del ingreso esperada bajo cada régimen; la

\footnotetext{
${ }^{16} \mathrm{O}$, lo que es lo mismo: $\log [\alpha r+\tau p(1-\alpha r-\lambda \tau p)]+\log y \geq(1-q) \log S R y+q(\log s \mu y)$

${ }^{17}$ Los términos que dependen de $y$ se cancelan.
} 
probabilidad que tiene cada grupo de imponer su propia dictadura como resultado de un enfrentamiento, el costo asociado a los impuestos, y la constante $\mu$ que afecta la utilidad del consumo bajo un régimen dictatorial ${ }^{18}$.

Las comparaciones interpersonales de consumo con otros individuos de la misma sociedad son un factor crucial para la estabilidad de la democracia en este modelo, mientras que las preferencias por la democracia (o contra la dictadura) se mantienen completamente constantes frente a cualquier aumento en los niveles medios de ingreso y de consumo. Como consecuencia, puede afirmarse que el supuesto de utilidad marginal decreciente del ingreso no es una condición suficiente para concluir que la estabilidad de la democracia se incrementa en la medida que una sociedad se vuelve más rica, incluso si se asume que la utilidad que extraen del consumo los opositores de un régimen dictatorial es menor a la que podrían obtener si vivieran en democracia.

En este modelo, por sobre todo importan para la estabilidad democrática las comparaciones interpersonales de consumo con otros individuos, en la medida que la utilidad instantánea que el rico obtiene bajo democracia depende fuertemente del nivel de impuestos. De acuerdo con (2.2) bajo una democracia el votante mediano (que es pobre) elige su tasa impositiva mediante una comparación de su ingreso relativo al de todos las demás personas. Incluso la variable $(\alpha p)$ - que es menor que 1 - expresa el ingreso del pobre como fracción del promedio de todos los ingresos $(y)$. Por lo tanto, la expresión (1- $a \not p$ puede ser vista y representarse como una medida de desigualdad ( $\theta)$ que aumenta siempre que la brecha entre los ingresos de los ricos y los de los pobres se incrementa:

$$
\tau p= \begin{cases}\frac{\theta}{2 \lambda} & \text { si } \frac{\theta}{2 \lambda} \leq 1 \\ 1 & \text { si } \frac{\theta}{2 \lambda}>1\end{cases}
$$

Sustituyendo se puede demostrar que la utilidad de los ricos en democracia es:

18 Es más probable que la democracia se estabilice cuanto mayor sea la proporción del ingreso correspondiente a los ricos luego de impuestos y cuanto mayor sean las probabilidades de este grupo de ser derrotado en un conflicto violento. Por el contrario las probabilidades de un conflicto violento se incrementa cuanto mayor es la proporción del ingreso que le corresponde a los ricos en una dictadurade los pobres- $y$ cuanto menor es el parámetro que afecta la utilidad del consumo bajo una dictadura. 
(2.7) $\operatorname{Ur}(\tau p)\left\{\begin{array}{lr}\log \left(1-\pi(1-\theta)-\frac{\theta^{2}(1+\pi)}{4 \lambda}\right)-\log (1-\pi)+\log (y) & \text { si } \frac{\theta}{2 \lambda} \leq 1 \\ \log (1-\lambda)+\log (y) & \text { si } \frac{\theta}{2 \lambda}>1\end{array}\right.$

Recordemos que según 2.5 los ricos optaban por democracia si $U r(\tau p) \geq E U r$ $(R)$. Por lo tanto la función 2.7 puede usarse para evaluar las probabilidades de quiebre de la democracia, como se hace por ejemplo en la figura 3, asignando algunos valores arbitrarios a los parâmetros de la función. Y para la generalidad de los casos de (2.7) se deduce que si las demás condiciones permanecen idénticas, la utilidad de vivir bajo democracia para los ricos puede aumentar de forma consistente con pequeños o moderados incrementos de la desigualdad. Pero si la desigualdad aumenta más allá de cierto nível, la utilidad de vivir en democracia comienza a disminuir como consecuencia del término cuadrático en (2.8). La explicación de este fenómeno es que al aumentar la desigualdad también lo hacen los incentivos para aumentar los impuestos. Así cuando $(\theta)$ es alta, los ricos pierden ingresos por dos vías: pagan más por impuestos y además más ingreso total se esfuma debido a las pérdidas marginales asociadas a la redistribución. 
Figura 3 - Utilidad instantánea que los ricos extraen de obedecer a la democracia o rebelarse, como función de la distribución relativa del ingreso

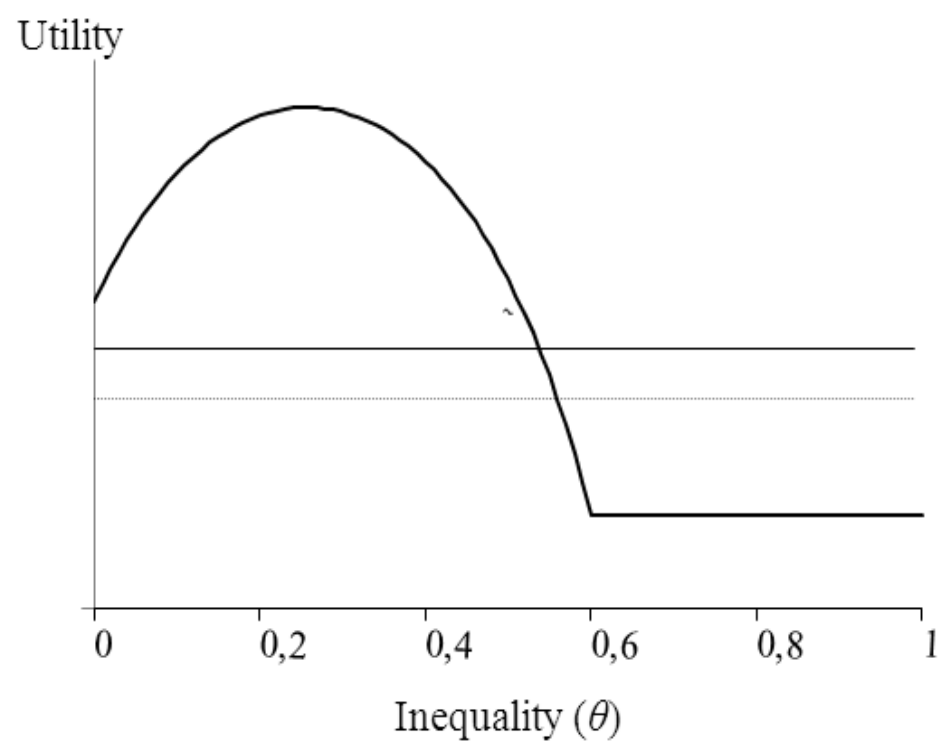

Obedecer la democracia (línea sólida ancha con curvaturas), rebelarse (línea sólida angosta cuando el poder militar de los ricos es mayor, $q=0.45$ ) o línea punteada (cuando el poder militar de los ricos es menor $q=0.5$ ). La figura fue construida suponiendo los siguientes valores: $\lambda=0.3, \mu=0.4$ y que los pobres $(\pi)$ representan 0.75 de la población total, mientras los ricos son el restante 0.25 . Fuente: Elaboración propia.

La utilidad de los ricos - de quienes depende el quiebre de la democracia puede apreciarse en la figura 3 que compara la utilidad instantánea que se deriva de obedecer a la democracia o rebelarse, a medida que la desigualdad aumenta. Cómo se explicó, una vez que se superan niveles moderados de desigualdad, la utilidad de la democracia comienza a descender, y a niveles suficientemente altos de desigualdad la utilidad de rebelarse comienza a superar a la utilidad de obedecer. La posibilidad de la rebelión puede depender del balance de fuerzas militares $(q)$ - que se refleja con dos líneas horizontales diferentes que reflejan distinto nivel de poder militar para los ricos - pero la conclusión general es que a alto niveles de desigualdad la estabilidad de la democracia está comprometida ${ }^{19}$.

\footnotetext{
${ }^{19}$ Cuando $\theta$ es mayor que 0.6 entonces $\tau p^{*}=1$, y por lo tanto de ahí en más la utilidad de la democracia para los ricos es una constante.
} 
En conclusión, en este modelo, las preferencias por la democracia dependen fuertemente de la distribución del ingreso que determina el nivel de impuestos, un resultado conciliable con la irregular historia democrática y regresiva distribución del ingreso en América Latina. En cambio las preferencias por la democracia permanecen completamente constantes frente a cualquier cambio o incremento en los niveles de consume medios (PBI per capita) si estos no alteran la distribución del ingreso. Por lo tanto, el solo cambio en la función de utilidad del consumo hacer caer las conclusiones de Przeworski (2005) pero además es posible concluir, contradiciendo lo afirmado en Przeworski (2006 y 2008) que el supuesto de utilidad marginal decreciente del consumo y el crecimiento del producto per cápita no son condiciones suficientes para estabilizar la democracia.

\section{Discutiendo acerca de la utilidad del consumo}

La forma matemática (1) elegida por Przeworski (2005) para representar la utilidad del consumo, es funcional para que el modelo llegue a la conclusión de que las democracias duran más conforme las sociedades se enriquecen. Los supuestos de un modelo requieren su justificación (MORTON, 1999), pero no es sencillo encontrar argumentos que sustenten la particular función de utilidad (1), sobre todo desde que pudo haberse optado por una función alternativa (3), que cumple con los mismos requisitos fundamentales que la otra, pero que alejaría al modelo de su principal resultado. Más allá del modelo formal, vale la pena entonces ocuparse de la lógica cruda que sostiene la presunción de que el enriquecimiento absoluto de los países mejora las probabilidades de sostener la democracia.

En tal sentido, la intuición básica que guía el modelo de Przeworski es novedosa: en una democracia rica hay mucho para perder si sobreviene una dictadura, y por eso las partes que podrían entrar en conflicto moderan sus expectativas distributivas para evitar este desenlace tan temido. No ocurriría lo mismo en la democracia de un país pobre, donde no habría tanto para perder. Sin embargo, este argumento puede ser objeto una serie de objeciones que atacan su base misma.

Para Przeworski, las personas tendrían la capacidad de abstraerse de alguna manera y de comparar sus niveles de consumo con el de otras sociedades o tiempos históricos, y si encuentran que este nivel de consumo es alto, deciden relativizar la importancia de las comparaciones interpersonales de consumo con los pares de su propia sociedad, y aceptan la redistribución del ingreso que la democracia les depare. Este ejemplo proporcionado por el propio Przeworski intenta ilustrar el punto: 
Si la elección presidencial estadounidense de 2000 hubiese ocurrido en un país con la tercera parte del ingreso de los EE.UU. habría terminado en un golpe de Estado o en una Guerra Civil, como sucedió en Costa Rica en 1948. Estos resultados no se produjeron porque la gente en Estados Unidos tiene mucho que perder. Probablemente dijeron "Bueno, vamos a ser gobernados por un presidente que probablemente se robó la elección, no tiene legitimidad y nos desagrada. ¿Y qué? Sobreviviremos. Tenemos nuestras casas, nuestros autos y nuestros televisores. Entonces, ¿para qué molestarse? Hay demasiado en juego como para salir a la calle, construir barricadas o lo que sea (MUNCK y SNYDER, 2007, p. 471).

El razonamiento es interesante y original, pero justificarlo a la luz de la teoría y de la evidencia empírica sobre la utilidad del consumo no parece nada sencillo. Hasta ahora se ha considerado que las personas efectúan comparaciones interpersonales de consumo con sus pares o con el promedio de su propia sociedad cuando eligen sus posiciones políticas. Esto resulta lógico en tanto los seres humanos estamos acostumbrados a experimentar determinados niveles de consumo; y somos concientes de que estos niveles de consumo social son pasibles de redistribución entre los individuos que integran nuestra comunidad política. Nuestra propia experiencia y la plausibilidad de su transformación política, es la base para las comparaciones interpersonales de consumo con nuestros pares.

Mientras tanto en el argumento de Przeworski, las personas perciben la utilidad que le reportan los niveles de consumo de su sociedad como altos o bajos en términos absolutos. Para experimentar esto, deberían ser capaces de efectuar una comparación tácita o explícita con otros tiempos o sociedades, y luego actuarían políticamente movidos por este tipo de consideraciones. Sólo así podrían las personas valorar y respetar más la democracia conforme aumentan los niveles medios de consumo de una sociedad. Se sustituiría la importancia de la comparación de los niveles de consumo relativo de los individuos de una sociedad entre sí, por una comparación con los niveles medios absolutos de consumo de otras sociedades o tiempos históricos.

Entretanto diversos investigadores han reportado que el incremento absoluto del consumo no parece reportar mayores niveles de utilidad a nivel subjetivo (EASTERLIN, 1974 y 2005; FRANK, 1997) y este resultado paradójico ha sido explicado por un incremento constante de las expectativas sociales; por adaptación a mayores niveles de consumo; y por la importancia de las comparaciones interpersonales de consumo con los miembros de la misma sociedad. De ahí que dos grandes objeciones 
podrían hacerse al razonamiento de Przeworski a partir de la teoría y la evidencia existente sobre la utilidad del consumo.

En primer lugar, podría objetarse la noción misma de que en algunas sociedades "se arriesga mucho porque son ricas", mientras que en otras sociedades "se arriesga poco porque son pobres". Los individuos parecen adaptarse y acostumbrase a los cambios de ingresos (BURCHARDT, 2005) de tal modo que su sensación subjetiva de bienestar no aumenta sostenidamente con el aumento absoluto del consumo (BRICKMAN y CAMPBELL, 1971; FREDERICK y LOEWENSTEIN, 1999). Una mejora de consumo puede provocar un efecto efímero de bienestar que luego se diluye (GRUND y SLIWKA, 2003) y en la medida que la gente no es conciente del fenómeno, continúa buscando más bienes materiales.

Este fenómeno de psicológico de adaptación (HELSON, 1964) va en contra de la idea de que en las sociedades ricas, la utilidad que se extrae del consumo es cualitativamente distinta a la de las sociedades más pobres. Por lo tanto dos sociedades con muy distintos niveles de ingresos pueden extraer una utilidad similar del consumo, producto de la adaptación social con el transcurso del tiempo (ESTERLIN, 2005). Si los niveles de utilidad extraídos del consumo no difieren sensiblemente, sencillamente la utilidad derivada del consumo no aumentaría en el largo plazo con el incremento de los ingresos.

No sería entonces posible que llegado a cierto nivel de consumo, los individuos sean capaces de sentir niveles tan altos de utilidad como para decidir que vale la pena dejar de luchar por la redistribución ${ }^{20}$. Si las expectativas se adaptan y crecen con la producción y el consumo (ROUSSEAU, 1999 [1754]; SMITH, 2007 [1776]) "mucho" y "poco" no significarán lo mismo en dos tiempos históricos diferentes o en dos sociedades distintas.

Además, si perder la democracia implica un riesgo constante que le resta utilidad a todo lo que se consume - como necesita afirmar Przeworski (2005) - no parece sencillo afirmar que ésta inseguridad representa una mayor pérdida de utilidad en una sociedad $x$, que en una sociedad $y$. Es difícil sostener que la vida, la seguridad o la libertad valgan más para un ser humano en una sociedad o en otra, dependiendo de sus niveles de ingreso o de consumo.

\footnotetext{
${ }^{20}$ Se dirá que un país rico ya los bienes materiales no importan tanto, pero si los bienes materiales no importan, ¿por qué las personas gastan su tiempo para producirlos? Y si la distribución de los bienes ya no interesa ¿por qué las sociedades continúan repartiendo el esfuerzo del trabajo y la retribución del mismo en forma desigual?
} 
En segundo lugar, la utilidad que se extrae del consumo por una persona parece depender más de comparaciones interpersonales de consumo con otros individuos de su mismo contexto social, que del consumo alcanzado en términos absolutos (GAERTNER, 1974; POLLAK, 1976; MC BRIDE, 2001; LAYARD et al., 2009; STUTZER, 2004; KNIGHT, SONG y GUNATILAKA, 2006). Los seres humanos buscan el reconocimiento social (POLANYI, 1944; HIRSCH, 1995) y las preferencias se construyen así con el ambiente y la comparación con el bienestar de los pares (TOMES, 1986). Este mismo tipo de motivaciones es lo que podría estar detrás de los conflictos distributivos.

En tal sentido las personas parecen competir por los bienes y status relativo, y por lo tanto incrementar los ingresos de todos, podría no aumentar la utilidad de todos. Si las preferencias distributivas y de consumo se construyen en la comparación con los miembros de un mismo contexto social (VEBLEN, 1994[1899]), entonces la presión redistributiva no estaría ligada a los niveles absolutos de consumo de toda la sociedad (MARX, 1966[1849] ${ }^{21}$ ). En dos sociedades con patrones similares de distribución de los recursos económicos, del esfuerzo y del ocio, las presiones redistributivas podrían ser también bastante parecidas, a pesar de que los niveles absolutos de consumo sean muy diferentes.

Los conflictos redistributivos no disminuirían entonces constantemente con los niveles absolutos de consumo, una hipótesis bastante plausible a la luz de la propia evidencia histórica y antropológica (DAHL, 1992; HUNTINGTON, 2012; BOLLEN y PAXTON, 1997; TRAVERSA, 2011). Es interesante comprobar que la experimentación parece corroborar esta hipótesis. Los individuos parecen preferir niveles de consumo absolutos más bajos si se les asegura una mejor posición social relativa, que niveles de consumo más altos pero empeorando la posición social relativa. Esta tendencia a la comparación relativa y a la respuesta conductual en función de estos criterios ha sido probada incluso en la experimentación con animales (BROSNAN y DE WAAL, 2003).

Por lo tanto no resulta razonable asumir sin discusión, que mayores niveles de consumo absoluto son percibidos como tales, y que alcanzan para desplazar políticamente a las preferencias distributivas construidas en base a comparaciones relativas de consumo con los pares de una misma sociedad. Dada la importancia de este

\footnotetext{
${ }^{21}$ Karl Marx expone así su visión sobre el asunto en Trabajo Asalariado y Capital: "Una casa puede ser grande o pequeña, siempre y cuando las casas que la rodean sean igualmente pequeñas servirá para satisfacer todas las exigencias sociales de una vivienda. Pero si se levanta un palacio al lado de la casita, esta se encoge y se transforma en una choza” (MARX, 1966[1849], p. 80).
} 
supuesto para conseguir argumentar que el nivel de producto explica la duración de la democracia, habría que concentrar más esfuerzos de investigación teórica y empírica para sustentar su validez. Y como se ha visto, por el momento existen numerosos antecedentes en la literatura que contradicen tal presunción.

\section{¿Qué clase de equilibrio democrático?}

Además de los cuestionamientos previos, otras interesantes derivaciones surgen relacionadas con la noción misma de la democracia como un equilibrio entre dos actores con capacidad de derribarla. En esta lógica la democracia emergería como un equilibrio auto-reforzado, en el que cada una de las dos posiciones distributivas en conflicto (los ricos y los pobres) deciden que es conveniente respetar las reglas del juego democrático, antes que arriesgarse a perder utilidad debido a una dictadura del otro bando. Pero si una de las partes en conflicto percibiera que la otra es incapaz de castigar un accionar desleal contra la democracia, ¿por qué no intentar establecer su propia dictadura e imponer todas sus pretensiones distributivas?

La experiencia histórica parece ilustrar que justamente una de las partes en los conflictos distributivos cuenta con mejores probabilidades de quebrar con las instituciones democráticas para imponer sus preferencias. Casi la totalidad de los quiebres de las democracias en el mundo durante el siglo XX, se resolvieron a favor de las posiciones de las élites socio-económicas. Esta conclusión tan controversial, recoge altos grados de coincidencia entre pensadores de muy distinto signo ideológico (HOBSBAWM, 1990; HUNTINGTON, 2012).

Por lo tanto, aun dejando de lado los cuestionamientos de la sección anterior sobre la función de utilidad del consumo, para que la democracia se transforme en un equilibrio auto-reforzado es necesario que las dos partes en conflicto consideren que la otra parte tiene fuerza suficiente como para responder y castigar cualquier agresión a la democracia. Pero la historia muestra que el riesgo asociado a llevar adelante una acción de este tipo puede ser muy bajo, al menos para una de las partes en conflicto ${ }^{22}$. Y los costos son aún más bajos, si los cálculos de los actores se limitan a evaluar las pérdidas de utilidad del consumo debido a la inseguridad física, ya que para las élites la seguridad de sus personas y de sus bienes bien puede estar a mayor resguardo bajo algunas dictaduras que en democracia.

\footnotetext{
${ }^{22} \mathrm{Y}$ no faltan en general individuos dispuestos a arriesgar la posibilidad de un castigo a cambio de acceder al poder por la fuerza.
} 
El mismo argumento del modelo bien puede tomar entonces un giro radical, cuyas consecuencias son de sobra conocidas por quienes han sufrido en carne propia la inestabilidad de las instituciones democráticas en algunas sociedades desiguales. Es frecuente que quienes dan por tierra con las instituciones democráticas, reivindiquen la necesidad de restaurar el orden y la seguridad, en particular frente a los conflictos distributivos. En tal sentido una dictadura bien podría reclamar para sí la legitimidad que se deriva de imponer el orden, que permitiría generar progreso material y disfrutar de estos logros con seguridad.

En síntesis no es descabellado pensar que en algunos contextos de gran desigualdad, buena parte de la sociedad podría percibir una función de utilidad del consumo exactamente contraria a la ilustrada en la Gráfica 1. Si la dictadura la asegura una mayor seguridad y protección de la propiedad, las funciones de utilidad del consumo se invierten. Esta ha sido, y aún parece ser, la forma de pensar de muchas personas en regiones muy desiguales ${ }^{23}$. Pero además existe otra vía alternativa por la que los quiebres de la democracia no necesariamente implicarían una pérdida de utilidad del consumo debido a la inseguridad. El fraude electoral o la suplantación de un poder de gobierno por otro, son igualmente lesivos del juego democrático. Sin embargo estas prácticas reducen fuertemente los costes asociados al quiebre, ya que quienes los promueven podrían incluso manifestar en todo momento la intención de respetar el Estado de Derecho, y no necesariamente existiría la represión e inseguridad generalizadas que justifica la pérdida de utilidad de la función (1). Existen entonces formas menos costosas de quebrar con la democracia, que igualmente pueden servir a un grupo para evitar o para retrasar que un gobierno democrático aplique políticas redistributivas indeseadas ${ }^{24}$.

Más aún, en esta lógica, los quiebres democráticos o el veto violento a las políticas de un gobierno democrático, podrían convertirse en fuerzas faciliten el equilibrio democrático futuro. En efecto, el equilibrio propuesto por Przeworski se sustenta en última instancia en el temor que cada parte tiene respecto de la violencia que podría ejercer la otra. Así, la experiencia traumática de un terrible golpe de Estado, podría llevar a la población a moderar sus preferencias distributivas para evitar que la historia vuelva a repetirse (TRAVERSA, 2011). La pregunta que debemos hacernos entonces, es qué tipo de democracia nos deja este equilibrio. Si la democracia implica

\footnotetext{
${ }^{23}$ En tal sentido los últimos datos liberados al público del Latinobarómetro (2009) revelan que el principal problema de las democracias latinoamericanas según los encuestados, es su incapacidad para luchar contra el crimen y la inseguridad.

${ }^{24}$ Las últimas crisis políticas en Honduras y Paraguay parecen pasibles de esta interpretación.
} 
expresar las preferencias en libertad, esto ya no se parece a un cabal equilibrio democrático.

\section{Conclusión}

Una explicación sobre la causa de un acontecimiento, no se agota con una generalización empírica, es una demanda para que la estructura del hecho en cuestión se haga comprensible (HANSON, 1958). Przeworski (2005) aporta una explicación para la asociación empírica entre el producto bruto y la democracia. Se basa en un complejo modelo analítico, pero en realidad parte de un supuesto que conlleva implícito en sí mismo el resultado de que la democracia es más valiosa conforme las sociedades se vuelven más ricas. Por lo tanto, con la inclusión de su supuesto sobre la utilidad del consumo, el modelo se vuelve particularmente auto-recursivo y trivial ${ }^{25}$.

Tal vez consciente de la importancia cardinal del supuesto sobre el que se sustenta todo el modelo, en otros dos trabajos posteriores Przeworski (2006 y 2008) ha sugerido que las mismas conclusiones podrían conseguirse si lo relajamos y sólo asumimos el razonable supuesto de la utilidad marginal decreciente del consumo. Esta presunción es errónea, y aquí se demostró mediante un modelo casi idéntico al de Przeworski (2005) incluyendo el supuesto de la utilidad marginal decreciente del ingreso y la valoración de la democracia por parte de los ciudadanos. La conclusión de este modelo, es que la estabilidad democrática no se ve favorecida en absoluto por un incremento en los niveles de producto per cápita, pero si se ve afectada por una desigual distribución de ingreso, tal como sostuvieran algunos de los aportes más influyentes del pensamiento social latinoamericano.

La discusión resulta particularmente relevante en función de algunas tendencias recientes de la literatura en torno a la democracia, el desarrollo económico y la desigualdad. En su formulación inicial, la relación entre desarrollo y democracia se interpretaba como intermediada por la distribución del ingreso. Para Lipset (1959) la expansión de los sectores medios era consecuencia del desarrollo y un factor

25 En otras palabras: la explicación propuesta por Przeworski es sustentable desde un punto de vista lógico - cómo lo son otras - pero no requiere de un modelo para exponerse. El ejemplo puede ser ilustrativo del espacio que ocupan la matemática y los modelos analíticos en las ciencias sociales. Tal vez sino se elaborara un modelo, la explicación propuesta no merecería tanta atención; así la propia complejidad barroca e innecesaria en el modelo de Przeworski (2005), tal vez se relaciona con su propio éxito y prestigio producto de un consumo snob de los mismos. Es posible que buena parte de quienes conocen sus conclusiones y lo citan, valoran esta complejidad por el estatus que confiere, aunque no estén al tanto de que uno de sus supuestos trae ya implícito la conclusión final. Queda claro que este no es un problema de los modelos analíticos en sí mismos ni de su potencial heurístico. 
fundamental para explicar la democracia. La teoría de la modernización exógena que aquí se analizó supone un viraje importante, pues se saltea la distribución del ingreso para señalar un rol estabilizador directo del producto per capita.

El cambio no es menor, toda vez que la economía política ha señalado recurrentemente la existencia de una disyuntiva entre los objetivos distributivos y la búsqueda de eficiencia económica para el crecimiento de la producción (OKUN, 1972; MELTZER y RICHARDS, 1981) ${ }^{26}$. En otras palabras, si se integran estos postulados, podría razonarse que la búsqueda de la igualdad mediante la redistribución sería en sí misma perjudicial para la estabilidad democrática por afectar los niveles de producto (TRAVERSA, 2011).

Esta tensión entre eficiencia y redistribución vuelve muy pertinente a la pregunta respecto a los mecanismos causales que se encuentran detrás de la asociación estadística entre el desarrollo y democracia ${ }^{27}$. La respuesta de Przeworski (2005) resulta innovadora y radical por sus consecuencias: ¿puede pasar la distribución del ingreso a un segundo plano y concentrarnos únicamente en la condiciones para aumentar el producto cuando el problema es la estabilidad democrática? La mera formulación de esta pregunta parece relacionarse con el panorama general de las democracias contemporáneas: son cada vez más estables y con mayores niveles medios de consumo, pero en un contexto de desencanto político y sin brindar solución a los viejos dilemas materiales de la desigual distribución del ingreso e incluso de la pobreza.

Poco hay de casual en este panorama, en los últimos cuarenta años las democracias han mostrado importantes problema para redistribuir, $y$ eso se ha relacionado con la expansión de los sectores medios y trabajadores calificados, que quitan cohesión a las coaliciones redistributivas (TRAVERSA, 2015). Es justamente el desarrollo económico quien requiere la calificación técnica de una parte de la mano de obra, y así ha estado asociado a la expansión de los sectores medios, que diluyen las amenazas redistributivas radicales y facilitan la estabilización democrática.

Por lo tanto, la expansión de los sectores medios (LIPSET, 1959); la expansión del consumo absoluto (PRZEWORSKI, 2005); las tasas anuales de crecimiento

\footnotetext{
${ }^{26}$ Los modelos analíticos más reconocidos (MELTZER y RICHARDS, 1981) concluyen la existencia de esta disyuntiva entre igualdad y eficiencia (OKUN, 1972), y a partir de allí, la existencia de esta tensión se incorpora como un dato o supuesto de la realidad en los análisis más influyentes en Ciencia Política (BOIX, 2003; ACEMOGLU y ROBINSON, 2005; PRZEWORSKI, 2005).

${ }^{27}$ Además debe recordarse que algunas contribuciones recientes han criticado la asociación entre la renta per cápita y la democracia incluso en el plano estadístico (ACEMOGLU et al., 2008).
} 
estables (O’DONNELL, 1973; PREBISCH, 1981) y los cambios en valores y actitudes (INGLEHART y WELZEL, 2005) son todos fenómenos que han ido de la mano, y es casi imposible discernir con claridad cuál de estos factores favoreció la estabilidad democrática y en qué medida lo hizo. Algo cambió y las democracias ya no quiebran tanto como antes, pero no podemos decir con exactitud en qué consistió este cambio; sin embargo en este contexto, las explicaciones que han hecho énfasis en los conflictos distributivos y los cambios en la estructura de clases siguen completamente vigentes, y son absolutamente sólidas desde un punto de vista teórico, como demostró el modelo aquí desarrollado.

- Federico Traversa é Doutor em Ciência Politica pela Universidade de Salamanca. É Professor do Instituto de Ciência Política da Universidade da República do Uruguai e Pesquisador da Agência Nacional de Investigação e Inovação do Uruguai. E-mail: traversa@cienciassociales.edu.uy.

\section{Referências}

ACEMOGLU, Daron; ROBINSON, James A. Economic Origins of Dictatorship and Democracy. 1 ed. Cambridge: Cambridge University Press, 2005.

ACEMOGLU, Daron et al. Income and Democracy. American Economic Review, v. 98, n. 3, p. 808842, 2008).

ACEMOGLU, Daron et al. Reevaluating the Modernization Hypothesis. Journal of Monetary Economics, v. 56, p. 1043-1058, 2009.

ARISTÓTELES. The Organon. CreateSpace Independent Publishing Platform, 2012.

BOIX, Carles. Democracy and Redistribution. Cambridge: Cambridge University Press, 2003.

BOIX, Carles; MILLER, Michael; ROSATO, Sebastián. A complete Data Set of Political Regimes, 1800-2007. Comparative Political, vol. 46, no 12, p. 1523-1554.2013.

BOLLEN, Kenneth A.; PAXTON, Pamela. Democracy before Athens. In: MIDLARSKY, Manus I. Inequality, Democracy, and Economic Development. Cambridge: Cambridge University Press, 1997. p. 13-44

BRICKMAN, Phillip; CAMPBELL, D. T. Hedonic relativism and planning the good society. In: APPLEY, Mortimer H. Adaptation-level theory. New York: Academic Press, 1971. p. 287-305

BROSNAN, Sarah F.; WAAL, Frans B. Monkeys reject unequal pay. Nature, n. 425, p. 297-299, 2003. BURCHARDT, Tania. Are One Man's Rags Another Man's Riches? Identifying Adaptive Expectations using Panel Data. Social Indicators Research, v. 74, n. 1, p. 57-102, 2005.

CARDOSO, Fernando H.; FALETTO, Enzo. Dependencia y Desarrollo en América Latina. México, 
D.F.: Siglo XXI Eds., 1969.

CLARKE, Kevin A.; PRIMO, David M. Modernizing Political Science: A Model-Based Approach. Perspectives on Politics, v. 5, n. 4, p. 741-753, dez. 2007.

DAHL, Robert A. Democracy and Its Critics. New Haven, EUA: Yale University Press, 1992.

EASTERLIN, Richard A. Does economic Growth Improve the Human Lot? Some Empirical Evidence. In: Nations and households in economic growth: essays in honor of Moses Abramovitz (Abramovitz Moses,.). Academic Press, 1974.

EASTERLIN, Richard A. A puzzle for adaptive theory. Journal of Economic Behavior \& Organization, v. 56, n. 4, p. 513-521, 2005.

FRANK, Robert H. The Frame of Reference as a Public Good. Economic Journal, v. 107, n. 445, p. 1832-1847, 1997.

FREDERICK, Shane; LOEWENSTEIN, George F. Hedonic Adaptation. In: KAHNEMAN, Daniel (Org.). Well-Being: The Foundations of Hedonic Psychology. New York: Russell Sage, 1999.

GAERTNER, Wulf. A dynamic model of interdependent consumer behavior. Zeitschrift für Nationalökonomie, v. 34, n. 3-4, p. 327-344, 1974.

GARNER, Bryan A. A Dictionary of Modern Legal Usage. Oxford: Oxford University Press, 2001.

GRUND, Christian; SLIWKA, Dirk. The Further We Stretch the Higher the Sky: on the Impact of Wage Increases on Job Satisfaction. Bonn, Germany: University of Bonn, 2003.

HANSON, Norwood R. Patterns of Discovery: An Inquiry Into the Conceptual Foundations of Science. Cambridge: Cambridge University Press, 1958.

HELSON, Harry. Adaptation-level theory: an experimental and systematic approach to behavior. New York: Harper \& Row, 1964.

HIRSCH, Fred. Social Limits to Growth. London: Routledge \& Kegan Paul Ltd, 1977.

HOBSBAWM, Eric J. History and Illusion. New Left Review, I/220, nov.-dez, 1990.

HUNTINGTON, Samuel P. The Third Wave: Democratization in the Late 20th Century. Norman, US: University of Oklahoma Press, 2012.

HURLEY, Patrick J. A concise introduction to logic. Australia; Belmont, CA: Thomson/Wadsworth, 2008.

INGLEHART, Ronald; WELZEL, Christian. Modernization, Cultural Change, and Democracy: The Human Development Sequence. Cambridge: Cambridge University Press, 2005.

KNIGHT, John; SONG, Lina; GUNATILAKA, Ramani. Subjective Well-being and its Determinants in Rural China. China economic review, v. 20, n. 4, p. 635-649. 2009.

LAYARD, Richard G. et al. Does relative income matter? Are the critics right? Centre for Economic Performance, London, n. 918, 2009.

LIPSET, Seymour Martin. Some Social Requisites of Democracy: Economic Development and Political Legitimacy. Political Science, v. 53, n. 1, p. 69-105, 1959.

MARX, Karl. Wage Labour and Capital. Moscow: Progress Publishers, 1966 [1849].

MCBRIDE, Michael. Relative-income effects on subjective well-being in the cross-section. Journal of Economic Behavior \& Organization, v. 45, n. 3, p. 251-278, 2001.

MCBRIDE, Michael; MILANTE; Gary; SKAPERDAS, Stergios. Peace and War With Endogenous State Capacity. Journal of Conflict Resolution, v. 55, n. 3, p. 446-468, 2011.

MELTZER ALLAN y SCOTT RICHARDS. A rational theory of the size of government. The Journal of Political Economy, v. 89, n. 5, p. 914-927, 1981. 
MORTON, Rebecca B. Methods and Models: A Guide to the Empirical Analysis of Formal Models in Political Science. Cambridge: Cambridge University Press, 1999.

MUNCK, Gerardo L.; SNYDER, Richard. Passion, Craft, and Method in Comparative Politics. Baltimore: JHU Press, 2007.

O'DONNELL, Guillermo. Modernization and Bureaucratic-Authoritarianism: Studies in South American Politics. Berkeley: Institute of International Studies, University of California, 1973.

OKUN, Arhur M. Equality and Efficiency: The Big Tradeoff. Washington: Brookings Institution Press, 1972.

PERELMAN, Chaïm. The New Rhetoric and the Humanities: Essays on Rhetoric and its Applications. Berlim: Springer, 1979.

POLANYI, Karl. The Great Transformation: The Political and Economic Origins of Our Time. Boston: Beacon Press, 1944.

POLLAK, Robert A. Interdependent Preferences. American Economic Review, v. 66, n. 3, p. 309-320, 1976.

PREBISCH, Raúl. Capitalismo Periférico: Crisis y Transformación. México, D.F.; Fondo de Cultura Económica, 1981.

PRZEWORSKI, Adam. Democracy as an equilibrium. Public Choice, v. 123, n. 3-4, p. 253-273, 2005. PRZEWORSKI, Adam. Self-Enforcing Democracy. In: WITTMAN, Donald A.; WEINGAST, Barry R. (Eds.) The Oxford Handbook of Political Economy. Oxford, England: Oxford University Press, 2006. p. 312-329.

PRZEWORSKI, Adam. The poor and the viability of democracy. In: KRISHNA, Anirudh (Ed.). Poverty, Participation and Democracy: A Global Perspective. Cambridge: Cambridge UP, 2008. p. 125147

PRZEWORSKI, Adam et al. Democracy and Development: Political Institutions and Well-Being in the World, 1950-1990. 1 ed. Cambridge: Cambridge University Press, 2000.

PRZEWORSKI, Adam; LIMONGI, Fernando P. Modernization: Theories and Facts. World Politics, v. 49, n. 2, 155-183, 1997.

ROBINSON, Richard. Begging the Question. Analysis, v. 31, n. 4, p. 113-117, 1971.

ROUSSEAU, Jean Jacques. Discourse on the Origin of Inequality. Minneapolis, USA: Filiquarian Publishing, LLC, 2007.

RUSSELL, Bertrand. The Philosophy of Logical Atomism. Minneapolis, USA: University of Minnesota, 1919.

SMITH, Adam. Wealth of Nations: An Inquiry Into the Nature and Causes of the Wealth of Nations. Boston: MobileReference, 2007.

STUTZER, Alois. The role of income aspirations in individual happiness. Journal of Economic Behavior \& Organization, v. 54, n. 1, p. 89-109, 2004.

TAYDAS, Zeynep; PEKSEN, Dursun. Can states buy peace? Social welfare spending and civil conflicts. Journal of Peace Research, v. 49, n. 2, p. 273-287, 2012.

TOMES, Nigel. Income distribution, happiness and satisfaction: A direct test of the interdependent preferences model. Journal of Economic Psychology, v. 7, n. 4, p. 425-446, 1986.

TRAVERSA, Federico. La gran transformación de la democracia: de las comunidades primitivas a la sociedad capitalista. Montevideo: UdelaR, 2011.

TRAVERSA, Federico. Desigualdad, acción colectiva y redistribución: un nuevo indicador para una 
relación compleja. Revista Española de Investigaciones Sociológicas, n. 151, p. 167-184, 2015.

VEBLEN, Thorstein. Theory Of The Leisure Class. Londres: Penguin Books, 1994 [1899].

WITTGENSTEIN, Ludwig; OGDEN, C. K. Tractatus logico-philosophicus. Mineola, N Y.: Dover Publications, 1999.

WUCHERPFENNIG, Julian; DEUTSCH, Franziska. Modernization and democracy: Theories and evidence revisited. Living Reviews in Democracy, v. 1, 2009.

Texto recebido em 29 de fevereiro de 2016. Aprovado em 17 de março de 2016. 